\title{
A INFLUÊNCIA DAS REDES SOCIAIS NO DISCURSO DO SUJEITO DA PÓS-MODERNIDADE: O DIALOGISMO DAS RELAÇÕES QUE SE INSTAURAM ENTRE ENUNCIADOS
}

\section{ENSAIO TEÓRICO}

SILVA, Rita Barcelos da ${ }^{1}$

ARAÚJO, Michell Pedruzzi Mendes ${ }^{2}$

PICINATI, Suander Leonardo Doná ${ }^{3}$

BOF, Roberta Decarli 4

SILVA, Rita Barcelos da. Et al. A influência das Redes Sociais no discurso do sujeito da Pós-modernidade: $O$ dialogismo das relações que se instauram entre enunciados. Revista Científica Multidisciplinar Núcleo do Conhecimento. Ano 05, Ed. 02, Vol. 02, pp. 79-90. Fevereiro de 2020. ISSN: 2448-0959, Link de acesso: https://www.nucleodoconhecimento.com.br/educacao/influencia-das-redessociais

\section{RESUMO}

O sujeito da atualidade experiencia dos estímulos tecnológicos e culturais que reverberam de uma nova era essencialmente informativa. $O$ discurso do homem contemporâneo sofre com as influências de novos padrões de comportamento, que atravessam a história e os contextos, seja no ambiente familiar, de trabalho ou demais palcos da vida. Vivemos a instabilidade de uma vida moderna fragmentada, que afeta as relações discursivas dos indivíduos. Com o acesso facilitado aos diversos veículos

\footnotetext{
${ }^{1}$ Mestre em Ciência, Tecnologia e Educação (Faculdade Vale do Cricaré).

2 Doutor em Educação (PPGE-UFES).

${ }^{3}$ Mestrando em Ciência, Tecnologia e Educação (Faculdade Vale do Cricaré).

${ }^{4}$ Mestre em Ciência, Tecnologia e Educação (Faculdade Vale do Cricaré).
} 
de comunicação, eventos hostis acabam por virem implícitos em discursos malintencionados. Nesse sentido, o estudo em questão objetiva analisar como o sujeito imerso na tecnologia é influenciado e influência pelos/nos diversos atravessamentos. Concorrem como objetivos específicos: compreender como a sociedade tem reagido aos diferentes estímulos recebidos pelas mídias sociais; refletir sobre as transformações nos processos sócio comunicacionais do sujeito em seu contexto histórico; analisar os preconceitos instalados nos discursos veiculados nas mídias sociais. O trabalho é de base qualitativa com proposição de pesquisa bibliográfica. Como aporte teórico, buscaram-se as contribuições de Brait (2009), Bhabha (1998), Bauman (1999), Hall (2001), Rosemberb (2006) dentre outros. Por intermédio do estudo realizado, é percebido que, frequentemente, pessoas se apropriam das mídias digitais, para externarem discursos depreciativos e antiéticos, ou até mesmo propagarem inverdades. Na contramão dessa realidade inoportuna, advogamos que as ferramentas digitais, enquanto inovações tecnológicas, podem propiciar o estreitamento das relações humanas por intermédio dos discursos, considerando a pluralidade e as peculiaridades socioculturais e sociolinguísticas de cada indivíduo.

Palavras-chave: Discurso, mídias digitais, pluralidade.

\section{INTRODUÇÃO}

A nova era informativa é permeada por estímulos tecnológicos e culturais que reverberam de sua própria diversidade constituinte. O sujeito da atualidade experiência desse influxo de informações, sendo dialógica sua relação com os diversos contextos participativos (Hall, 2001).

A fluidez dos tempos modernos carrega consigo os aspectos de uma sociedade fragmentada, marcada pela heterogeneidade estrutural. Portanto, seria insensato negar, ou mesmo desdenhar, a densa transformação que o aparecimento da "modernidade fluida" abrolhou na condição humana. O fato de que o arcabouço sistêmico seja longínquo e inalcançável, congregado ao estado fluido e não estruturado do panorama contíguo da política-vida, muda aquela qualidade de um modo radical e solicita que repensemos os avelhantados conceitos que cerceavam 
suas narrativas. Como zumbis, esses conceitos são hoje mortos-vivos. O pontodestaque incide em saber se sua ressurreição, embora que em nova configuração ou encarnação, é imaginável; ou, se não for, como fazer com que eles tenham um funeral decente e diligente (Bauman, 1999).

Nesse contexto, é oportuno correlacionar à realidade tecnológica vigente com as mudanças desencadeadas pelo advento da Revolução Industrial. O crescimento acelerado das tecnologias proporcionou uma série de inovações para a sociedade. Uma que se pode destacar é a difusão da internet juntamente com o uso intensivo das redes sociais. Com o acesso facilitado aos diversos veículos de comunicação, são perceptíveis as mudanças comportamentais nas pessoas, que se sentem aptas a discorrer sobre qualquer assunto, ainda que sem uma devida qualificação. Também são evidentes condutas inadequadas por parte de indivíduos que desrespeitam o pensamento e a cultura alheia, expressando menosprezo por elementos característicos de outrem.

As denominadas Fake News também emergem dessa era tecnológica, em que as informações falsas são repassadas numa velocidade vertiginosa. Frequentemente, as pessoas que as recebem - sem criticidade sobre seu teor - transmitem ou simplesmente reproduzem inverdades. Se por um lado a informação e o conhecimento são de fácil acesso, em contrapartida, há pessoas mal-intencionadas que propagam informações não confiáveis, ou até mesmo são ofensivas em seus discursos.

Não são raras as manifestações de ódio narradas pelos noticiários. As querelas que incidem desses episódios em grande parte são etnocêntricas ou de cunho terrorista, em que se considera uma cultura superior às demais. $O$ desrespeito à diversidade tem se manifestado em frentes diversas, tais como: condição social, orientação sexual, origem, escolha religiosa, dentre outras.

Neste ínterim, implícito em um discurso mal-intencionado, frequentemente, pessoas são ridicularizadas e sofrem com o preconceito linguístico/cultural. Como já sinalizado por Bagno (1999), estigmas linguísticos se corporificam nos rótulos aplicados aos pontos de vista de outrem. 
Diante das questões supracitadas, urge a necessidade de compreendermos e valorizarmos a diversidade que permeia as relações tecidas em nossa sociedade. Partindo da premissa de que no desenvolvimento cultural do ser humano, o plano social precede o plano pessoal, carregamos parte de nossa cultura, e esta invariavelmente tem total relação com nossas ações sobre o mundo (Vigotski, 1991; 2010; 2011). Assim, não há como dissociar linguagem e cultura, tendo em vista que as duas estão imbricadas. Neste aspecto, inspirados em Laraia (2008), advogamos que todo sujeito é portador de uma cultura e esta é parte fundamental para a constituição da subjetividade humana e guiadora do nosso comportamento frente a situações cotidianas.

Estratégias que possam embargar práticas de intolerância, sejam elas de cunho linguístico e/ou cultural, não se consubstanciam sem uma devida reflexão acerca das respostas emitidas pela sociedade, frente às novidades que lhe são expostas. De tempos em tempos surgem novas tecnologias, e também variadas redes sociais. A questão é como a sociedade tem se comportado, se eticamente ou não, mediante esses avanços tecnológicos e diferentes novos estímulos.

Atualmente, a sociedade transita no que se acordou intitular Era Digital. Os computadores ocupam ambiente admirável e efetivo no atual padrão de sociabilidade que conforma todos os âmbitos da sociedade, comércio, política, serviços, entretenimento, informação, relacionamentos etc. As decorrências desse processo são manifestas, sendo que essas alterações impactaram no cenário social na procura pelo progresso e pela simplificação da vida e das práticas dos sujeitos. As tecnologias digitais permitiram uma nova grandeza dos produtos, da transmissão, arquivo e acesso à informação alterando o contexto econômico, político e social. No entanto, a dimensão mais relevante do computador não é ele em si, mas a capacidade de interligação, de formação de redes. Nesse sentido, com o aparecimento da internet no final dos idos de 1960, os conceitos de liberdade e imaterialidade passam a insurgir a leitura e a comunicação em rede, permitindo arquivar, copiar, desmembrar, recompor, deslocar e construir textos, expô-los e ter acesso a todo tipo de informação, de qualquer variedade, a todo o momento (Kohn; Moraes, 2007). 
Sendo assim, este estudo objetiva analisar como o sujeito imerso na tecnologia é influenciado e influência pelos/nos diversos atravessamentos. Concorrem como objetivos específicos: compreender como a sociedade tem reagido aos diferentes estímulos recebidos pelas mídias sociais; refletir sobre as transformações nos processos socio comunicacionais do sujeito em seu contexto histórico; analisar os preconceitos instalados nos discursos veiculados nas mídias sociais.

Como aporte teórico discute-se as questões do sujeito pós-moderno e o dialogismo das relações que se instauram entre enunciados, pelas vozes e contribuições de Buber (1974), Bhabha (1998), Bauman (1999), Hall (2001), Rosemberb (2006) e Brait (2009).

\section{PERCURSO METODOLÓGICO}

A pesquisa em questão é de caráter qualitativo calcado em estudo de cunho bibliográfico. Sobre as fontes de pesquisa adotadas, foi realizada uma vasta busca em acervos e bancos de teses, dissertações e artigos, com temática proximal ao proposto no presente estudo.

Com base na natureza bibliográfica, Gil (2008, p. 50) salienta que a mesma se constitui:

[...] a partir de material já elaborado, constituído principalmente de livros e artigos científicos. Embora em quase todos os estudos seja exigido algum tipo de trabalho desta natureza, há pesquisas desenvolvidas exclusivamente a partir de fontes bibliográficas. Parte dos estudos exploratórios podem ser definidos como pesquisas bibliográficas, assim como certo número de pesquisas desenvolvidas a partir da técnica de análise de conteúdo

No que tange ao aspecto qualitativo de pesquisa, e sua convergência ao estudo aqui apresentado, advogamos que a pesquisa de natureza bibliográfica responde a temas muito específicos. Preocupa-se, nas ciências sociais, com um plano de realidade que 
não pode ser expresso por números. Ou seja, trabalha com o mundo dos significados, motivos, anseios, crenças, denodos e estilos, o que corresponde a um espaço mais profundo dos arrolamentos (Minayo, 1994).

\section{LINGUAGEM, CULTURA E MÍDIAS SOCIAIS}

Desde a tenra idade o ser humano nasce com a necessidade de se comunicar, e a linguagem faz parte da existência da humanidade. De acordo com Buber (1974), as relações sociais se constituem por meio do diálogo, quando o processo não ocorre de maneira verticalizada. Mediante as interações comunicativas o indivíduo se constitui e se abre para novas perspectivas. A atividade comunicativa faz parte da essência do ser humano e é por meio dela que o sujeito externaliza seus anseios, percepções acerca da vida, igualmente exterioriza sua cultura, sendo esta basilar na formação do homem.

Tendo em vista que o sujeito é portador de uma cultura, isso traz consigo uma percepção de vida que irá moldar seu modo de pensar e agir. A comunicação, por sua vez, é uma espécie de função básica porque permite a interação social, ao mesmo tempo em que organiza o pensamento, transmite cultura, história, enfim socializa. Com o extravasamento das redes sociais, que passa a predominar sobre os processos de comunicação, algumas questões pertinentes emergem: dentro da realidade tecnológica vigente, como ocorre este diálogo? Há respeito por parte dos envolvidos neste universo digitalizado? Respeita-se a cultura alheia, o modo como externam seus pontos de vista? O discurso propagado é fidedigno? Qual a intenção por trás de quem propaga determinadas informações nas redes sociais?

Os apontamentos anunciados alertam sobre a necessidade de senso crítico na obtenção das informações e na propagação de determinadas notícias. Os meios sociais servem predominantemente às interações, e não para estigmatizar pessoas. Redes sociais, enquanto canais comunicativos, não devem vincular-se à fiscalização ou depreciação da maneira como o outro externaliza seu modo de pensar. 
A informação é a transmissão de mensagens que possuem um significado comum entre o emissor (quem produz a mensagem) e um sujeito (quem recebe a mensagem), por meio de um suporte tecnológico que faz a mediação dessa mensagem. Toda informação é dotada de consciência, objetivo e finalidade ao ser transmitida do emissor para o interlocutor (KOHN e MORAES, 2007, p. 2).

Como destacam Kohn e Moraes (2007), toda informação tem uma finalidade, ninguém produz um discurso ou propaga uma informação sem uma intencionalidade. Por isso, a importância de se analisar quem envia e qual é o objetivo desta ação. Bhabha (1998) enfatiza a necessidade dessa vigilância acerca das ações humanas e dos aspectos que reverberam das práticas sociais, para que se tenha uma percepção mais apurada do mundo circundante.

É sabido que o contexto histórico influencia no modo como a sociedade pensa, e como destaca Hall (2001), o sujeito na pós-modernidade vem sendo atravessado por diversas informações e também por diferentes culturas. Desta forma, não há como conceber uma sociedade monocultural, e sim, pluricultural. $\mathrm{O}$ apogeu das tecnologias trouxe repercussões profundas, tais como a segmentação da sociedade, não mais pautada em um discurso único e próprio, mas na polifonia dos discursos, que vão sendo incorporados e absorvidos pelos indivíduos. As transformações nos contextos interativos requerem olhares mais atentos e historicamente situados, para que se tenha uma melhor apreensão da realidade.

Sobre a polifonia dos discursos, Bakhtin contribui com a concepção de que o sujeito acaba carregando outras vozes em sua fala. Essa ideia é compatível ao anunciado por outros autores, tais como Brait (2009) e Hall (2001). Brait destaca o conceito de polifonia, expresso por textos que são atravessados por várias vozes equipolentes. Hall corrobora com a noção do sujeito transpassado por diversas culturas.

Bakhtin, primeiro estudioso a elaborar os conceitos de polifonia e heterogeneidade, defendeu a ideia de que todo texto é um objeto heterogêneo, de que todo texto é constituído por várias vozes, é a 
reconfiguração de outros textos que Ihe dão origem, dialogando com ele, retomando-o. Os sujeitos se constituem como tais nas ações interativas, sua consciência se forma no processo de interiorização de discursos preexistentes, materializados nos diferentes gêneros discursivos, atualizados nas contínuas e permanentes interlocuções de que vão participando (Pires; Tamanini-Adames, 2010, p. 71).

Como nos diz Bauman (1999), a sociedade contemporânea não apresenta uma unidade, não é homogênea, assim, os pensamentos são mudados constantemente. A sociedade é híbrida, heterogênea. Esse estudo relaciona-se também ao discurso produzido pelo sujeito na atualidade, que acaba reproduzindo outras vozes e culturas.

O discurso do sujeito contemporâneo sofre com as influências de novos padrões de comportamento, que atravessam a história e os contextos, seja no ambiente familiar, de trabalho ou demais palcos da vida. Vivemos a instabilidade de uma vida moderna fragmentada, que afeta as relações discursivas dos indivíduos.

Diante do exposto, é de extrema relevância entender que as redes sociais têm ocupado um papel preponderante na transmissão de informações e na formação do discurso. Frequentemente, pessoas se apropriam destes meios de comunicação, para externarem discursos depreciativos e antiéticos, ou até mesmo propagarem inverdades.

$\mathrm{Na}$ contramão desses eventos hostis, propomos uma reflexão sobre a face ética do discurso, condição sine qua non para a defesa de uma sociedade pluricultural e polifônica. De acordo com a definição dada pelo dicionário de Scottini (2014), ética significa "filosofia que estuda os valores morais, moral; valores profissionais". Depreende-se desta conceituação que, falar de ética vai além dos valores impostos pela sociedade e das convenções estabelecidas. Ser ético é querer o bem para o outro, argumentar com base em fatos, dados e informações confiáveis, exercitar a empatia por outrem, sem rotulações, julgamentos ou embates (Rosemberg, 2006). 


\section{POLIFONIA DISCURSIVA E MÍDIAS SOCIAIS: REFLEXÕES SOBRE O PRECONCEITO LINGUÍSTICO DISSEMINADO}

Os estudos da sociolinguística, principalmente do tipo variacionista, sinalizam que a língua não é um sistema homogêneo em si (Labov, 2008). Diferentes fatores influenciam no modo como o indivíduo exterioriza sua maneira de pensar. A língua pode sofrer variações conforme a idade, sexo, escolaridade, posição social dentre outros aspectos (Bagno, 1999; Bortoni-Ricardo, 2004), exprimindo o caráter multifacetado da sociedade contemporânea. No contexto brasileiro, esta variação é preponderante, tendo em vista as diversas influências recebidas com os processos de colonização e de imigração.

Desse modo, quando se fala em mídias sociais, é salutar pensar em um universo onde a pluralidade é presente. Ora, a internet tem adentrado casas e pessoas de locais dos mais longínquos, permitindo que variadas línguas e culturas tenham contato com a informação e com os meios de comunicação advindos desta nova era informativa.

Os discursos veiculados nas mídias alertam, entretanto, para o preconceito linguístico frequentemente disseminado. $O$ que se torna preocupante, quando se pensa no discurso preconceituoso, é quem sofre com este estigma. Em linhas gerais, as vítimas dos rótulos impostos sobre a falam são oriundas das camadas sociais menos favorecidas e de menor escolaridade. A procedência geográfica do indivíduo também tem sido alvo de injúrias e depreciações nos discursos virtuais.

O discurso de ódio é o conflito em si. Expor mensagens odiosas nas redes sociais contra as minorias: LGBTs (Lésbicas, Gays, Bissexuais, Travestis, Transexuais e Transgêneros), mulheres, negros, índios entre outras socialmente reprimidas, cria uma ruptura na rede e nas relações entre os atores. Atualmente a internet e por consequência as redes sociais são os principais meios para propagar o discurso de ódio. Os usuários através de seus perfis podem expor suas ideias, sentimentos, criar informação ou compartilhar informações com os nós da sua rede. 
Ativistas do ódio utilizam dessa ferramenta para compartilhar seu discurso (Nandi, 2018, p. 37).

Os estudos linguísticos auxiliam-nos no entendimento acerca das motivações implícitas nos discursos de ódio veiculados. O preconceito linguístico continuamente é derivado de posturas de recusa na aceitação do diferente. Em outras palavras, o indivíduo parte do pressuposto que somente sua visão de mundo é única e correta. Trata-se de questões que superam apenas o aspecto linguístico, mas abarcam ainda fundamentos históricos e ideológicos (Fernandes, 2014).

Em outras palavras, o discurso do ódio consiste na divulgação de mensagens que difundem e estimulam o ódio racial, a xenofobia, a homofobia e outras formas de ataques baseados na intolerância e que confrontam os limites éticos de convivência com o objetivo de justificar a privação de direitos, a exclusão social e até a eliminação física daqueles que são discriminados (STROPPA e ROTHENBURG, 2015, p. 456).

Depreende-se, desta forma, que a intolerância presente nos discursos, vincula-se à uma ótica limitada de determinados indivíduos sobre o potencial de transformação e sobre as múltiplas aprendizagens, proporcionados na/pela pluralidade dos contextos sociais. Quando o sujeito se abre para novas relações, ou melhor, para o diálogo horizontal, este indivíduo tem sua visão ampliada. Quando o processo dialógico ocorre, desprovido de qualquer preconceito ou julgamento, tanto um quanto o outro aprende (Buber, 1974).

\section{CONSIDERAÇÕES FINAIS}

O avanço tecnológico e o advento da nova era informativa são aspectos significativos que propiciaram às gerações contemporâneas um acesso facilitado às informações. O conhecimento é capaz de alcançar pessoas em diversos contextos, adentrando os espaços sociais, sem que seja necessário o deslocamento de seu público-alvo. 
Neste aspecto, são contribuições da internet. Entretanto, por outro lado, as transformações da sociedade no decorrer dos séculos, deixaram marcas negativas sob o uso consciente das mídias sociais e dos ambientes virtuais. O sujeito é por natureza um ser histórico e social, e estes fatores agem fortemente no modo como pensa, veste e fala. Sobre o comportamento dos atores sociais da época vigente, estudos têm apontado a falta de empatia e ausência de ética nos discursos sociais, principalmente no ambiente virtual. Soma-se a essa problemática, a difusão de notícias falsas, com o intuito de depreciar outrem, ou até mesmo eventos de intolerância com incitação ao ódio e apelo discriminatório.

$\mathrm{Na}$ contramão dessa realidade inoportuna, advogamos que as ferramentas digitais, enquanto inovações tecnológicas, podem propiciar o estreitamento das relações humanas por intermédio dos discursos, considerando a pluralidade $\mathrm{e}$ as peculiaridades socioculturais e sociolinguísticas de cada indivíduo.

Sendo assim, é preciso que seja incutida nas relações sociais e nas redes sociais disponíveis hoje com o advento da universalização da internet, uma cultura de respeito e apreço pela pluralidade dos grupos humanos e a consciência ética nos indivíduos acerca da confiabilidade e fidedignidade na produção e difusão das informações.

\section{REFERÊNCIAS}

BAGNO, Marcos. Preconceito linguístico: o que é, como se faz. São Paulo: Loyola, 1999.

BRAIT, Elizabeth (Org.). Bakhtin: dialogismo e polifonia. SP: Contexto, 2009.

BHABHA, Homi K. O local da cultura. Tradução de Myriam Ávila, Eliana Lourenço de Lima Reis, Gláucia Renate Gonçalves. Belo Horizonte: Ed. UFMG, 1998. 395 p. Coleção Humanitas

BAUMAN, Zygmunt. Modernidade Líquida. Tradução: Plínio Dentzien. Zahar. 1999. 
BORTONI-RICARDO, Stella Maris. Educação em língua materna: a sociolinguística na sala de aula. São Paulo: Parábola, 2004.

BUBER, Martin. Eu e Tu. Tradução do alemão, introdução e notas por Newton Aquiles Von Zuben. 2. ed. São Paulo: Moraes, 1974, 170 p.

GIL, A. C. Métodos e técnicas de pesquisa social. - 6. ed. - São Paulo: Atlas, 2008.

$\mathrm{KOHN}, \mathrm{K}$. Moraes, C.H. O impacto das novas tecnologias na sociedade: conceitos e características da Sociedade da Informação e da Sociedade Digital. Santos, 2007.

HALL, Stuart. A identidade cultural na pós-modernidade. Tradução Tomaz Tadeu da Silva, Guacira Lopes Louro. 5. ed. Rio de Janeiro: DP\&A, 2001.

LABOV, W. Padrões Sociolinguísticos. São Paulo: Parábola, 2008.

LARAIA, Roque de Barros. Cultura: um conceito antropológico. 22. ed.- Rio de Janeiro: Jorge Zahar. Ed, 2008.

MINAYO, M. C. de S. Pesquisa social: teoria, método e criatividade. 21. ed. Petrópolis: Vozes, 1994.

NANDI, José Adelmo Becker. $\mathrm{O}$ combate ao discurso de ódio nas redes sociais. Orientador: Giovani Mendonça Lunardi, 2018. 58 p. (TRABALHO DE CONCLUSÃO DE CURSO).

PIRES, Vera Lúcia; Tamanini-Adames, Fátima Andréia. Desenvolvimento do conceito bakhtiniano de polifonia. Estudos Semióticos. [on-line] Disponível em: http://www.fflch.usp.br/dl/semiotica/es. Editores Responsáveis: Francisco E. S. Merçon e Mariana Luz P. de Barros. Volume 6, Número 2, São Paulo, novembro de 2010, p. 66-76. Acesso em 06 de outubro de 2019.

ROSEMBERG, Marshall B. Comunicação não-violenta, Ágora, 2006. 
SCOTTINI, Alfredo. Dicionário escolar da língua portuguesa: 60.000 verbetes. Blumenau, SC: Todolivro, 2014.

SILVA, Rita do Carmo Polli. A Sociolinguística e a língua materna. Curitiba: Intersaberes, 2013.

STROPPA, Tatiana; ROTHENBURG, Walter Claudius. Liberdade de expressão e discurso do ódio: o conflito discursivo nas redes sociais. Revista Eletrônica do Curso de Direito da UFSM. v. 10, n. 2 / 2015.

VIGOTSKI, L. S. A formação social da mente. São Paulo: Martins Fontes, 1991.

VIGOTSKI, L. S. Psicologia pedagógica. São Paulo: Martins Fontes, 2010.

VIGOTSKI, L. S. A formação social da mente. São Paulo: Martins Fontes, 2011.

Enviado: Janeiro, 2020.

Aprovado: Fevereiro, 2020. 